\title{
REVIEW
}

\section{The role of short chain fatty acids in appetite regulation and energy homeostasis}

\author{
CS Byrne ${ }^{1}$, ES Chambers ${ }^{1}$, DJ Morrison ${ }^{2}$ and G Frost ${ }^{1}$
}

Over the last 20 years there has been an increasing interest in the influence of the gastrointestinal tract on appetite regulation. Much of the focus has been on the neuronal and hormonal relationship between the gastrointestinal tract and the brain. There is now mounting evidence that the colonic microbiota and their metabolic activity have a significant role in energy homeostasis. The supply of substrate to the colonic microbiota has a major impact on the microbial population and the metabolites they produce, particularly short chain fatty acids (SCFAs). SCFAs are produced when non-digestible carbohydrates, namely dietary fibres and resistant starch, undergo fermentation by the colonic microbiota. Both the consumption of fermentable carbohydrates and the administration of SCFAs have been reported to result in a wide range of health benefits including improvements in body composition, glucose homeostasis, blood lipid profiles and reduced body weight and colon cancer risk. However, published studies tend to report the effects that fermentable carbohydrates and SCFAs have on specific tissues and metabolic processes, and fail to explain how these local effects translate into systemic effects and the mitigation of disease risk. Moreover, studies tend to investigate SCFAs collectively and neglect to report the effects associated with individual SCFAs. Here, we bring together the recent evidence and suggest an overarching model for the effects of SCFAs on one of their beneficial aspects: appetite regulation and energy homeostasis.

International Journal of Obesity (2015) 39, 1331-1338; doi:10.1038/ijo.2015.84

\section{INTRODUCTION}

Obesity has become a global epidemic, with incidence rates of over $20 \%$ in the majority of western countries. ${ }^{1}$ It has been proposed that the current obesity epidemic may have been caused by a mismatch between the physiological mechanisms for maintaining energy balance, which evolved in response to ancestral diets, and the composition of the current western diet. $^{2}$ Over the past several decades, the western diet has changed significantly with the popularity of 'fast' and 'convenience' foods rapidly increasing. ${ }^{3}$ Such foods are energy dense, have a low dietary fibre content and produce lower satiety and satiation signals than low-energy dense foods. ${ }^{4}$ This diet is markedly different to the historical low-energy dense, nutrient-poor diet that the human gut was adapted to over several millennia. Evidence suggests that for most of history the human lineage consumed more indigestible plant material, such as grasses, sedges and tubers, than is present in a typical western-style diet ( $>100 \mathrm{~g}$ per day dietary fibre compared with $<15 \mathrm{~g}$ per day in the average modern-day diet), and is therefore likely to have contained a larger non-digestible component. ${ }^{5,6}$

Some carbohydrates resist digestion in the upper gastrointestinal tract and reach the large bowel mainly intact where they are subject to fermentation by the resident bacteria. The human gut microbiota is composed of $10^{13}-10^{14}$ microorganisms, accounting for $>1 \mathrm{~kg}$ of body weight. ${ }^{7,8}$ The gut microbiota is continuing to emerge as a major determinant of obesity and its associated health complications. ${ }^{9,10}$ However, as this topic is beyond the scope of the present review readers are referred to the excellent review by Holmes et al. ${ }^{11}$, which focuses on the composition and functional activities of the gut microbiota.

The principle products of the bacterial fermentation of nondigestible carbohydrates in the gut are short chain fatty acids (SCFAs), heat and gases. ${ }^{12-14}$ The process of bacterial fermentation serves as an energy harvest system for undigested material, rescuing energy that cannot be absorbed in the small bowel, and is used as a major energy source for some species. For example, lowland gorillas derive $\sim 57 \%$ of their metabolisable energy from SCFAs, compared with $1.2-10 \%$ in humans from the average western diet. ${ }^{15-17}$ The main SCFAs produced by bacterial fermentation are acetate, propionate and butyrate, and are present in the approximate molar ratio of $60: 20: 20 .^{18}$ It has been demonstrated that the consumption of soluble fermentable carbohydrates (FCs) increases the caecel content of SCFAs in animal models. ${ }^{19,20}$ The rate, ratio and extent of SCFA production, however, is a complex interplay between FC type, microbiome diversity and activity, and gut transit time..$^{21-25}$

Supplementing the high-fat diet of rodents with soluble FCs has been shown to protect against body weight and fat mass gain. ${ }^{26-28}$ Futhermore, research suggests that adult rodents who consume a weaning diet high in prebiotic fibre are protected against body weight gain when challenged with a western-style diet high in fat and sucrose. ${ }^{29}$ However, research carried out by Track et al. $^{30}$ suggests that the beneficial effects of FC consumption are specific to adolescent rodents. In addition to

\footnotetext{
${ }^{1}$ Nutrition and Dietetic Research Group, Division of Diabetes, Endocrinology and Metabolism, Section of Investigative Medicine, Faculty of Medicine, Hammersmith Campus, Imperial College London, London, UK and ${ }^{2}$ Stable Isotope Biochemistry Laboratory, Scottish Universities Environmental Research Centre, University of Glasgow, Glasgow, Scotland. Correspondence: Professor G Frost, Nutrition and Dietetic Research Group, Division of Diabetes, Endocrinology and Metabolism, Section of Investigative Medicine, Faculty of Medicine, Hammersmith Campus, Imperial College London, 6th Floor Commonwealth Building, DuCane Road, London W12 0NN, UK. E-mail: g.frost@imperial.ac.uk

Received 4 August 2014; revised 23 December 2014; accepted 19 April 2015; accepted article preview online 14 May 2015 ; advance online publication, 9 June 2015
} 
improvements in body composition, a number of research studies in humans have reported associations between the consumption of FCs and improvements in glucose homeostasis, insulin sensitivity and blood lipid profiles, however, these beneficial effects were not present in young healthy adults. ${ }^{31-36}$

Although it is known that greater FC consumption increases colonic SCFA production resulting in a wide range of health benefits, further research is needed to fully elucidate the molecular mechanisms by which SCFA mediate these effects. Published research often focuses on single mechanisms to explain the positive physiological effects associated with gut-derived SCFAs. However, we hypothesise that the beneficial effects reported are not the result of the activity of a single metabolic process on a specific tissue, but are more likely to be the result of the stimulation of a number of mechanisms activated in parallel. Here we review recent findings in this field and propose an interconnected picture of how SCFAs may affect appetite regulation and energy homeostasis.

\section{MATERIALS AND METHODS}

A review of the literature was conducted in 2014 using PubMed databases, with the following search terms: 'short chain fatty acids' AND dietary fiber(MeSH terms), 'short chain fatty acids' AND obesity(MeSH terms), 'short chain fatty acids' AND appetite(MeSH terms), 'short chain fatty acids' AND energy intake(MeSH terms), 'short chain fatty acids' AND energy expenditure(MeSH terms), 'short chain fatty acids' AND microbiota(MeSH terms), 'short chain fatty acids' AND ('free fatty acid receptor 3' OR 'GPR41' OR 'GPCR41') and 'short chain fatty acids' AND ('free fatty acid receptor 2' OR 'GPR43' OR 'GPCR43'). Reviews and research studies in which immune function or cancer progression/prevention were the primary focus were excluded as these topics were deemed beyond the scope of this review. Papers identified from the search were analysed by two of the authors and papers that were not relevant were rejected as shown in Figure 1. In total, 104 papers were identified as containing relevant primary evidence.

\section{SCFAs and free fatty acid receptor signalling}

In 2003, three independent research groups discovered that the orphan G-protein-coupled receptors, GPR43 and GPR41, were activated by SCFAs. ${ }^{37-39}$ These receptors have since been renamed free fatty acid receptor 2 and 3 (FFA2 and FFA3; formerly GPR43 and GPR41, respectively). Acetate and propionate are the

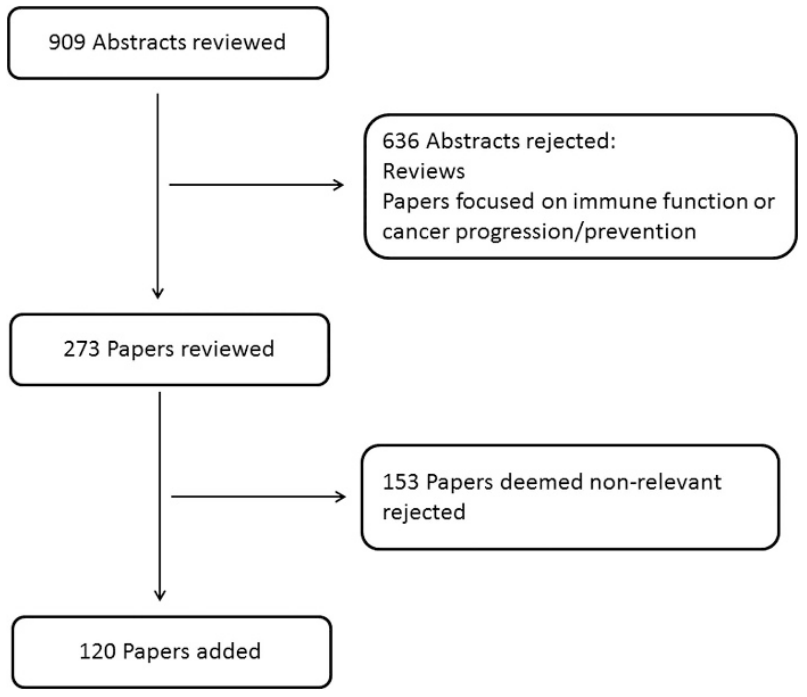

Figure 1. Flowchart outlining the methods used for research paper selection. most potent activators of FFA2, whereas FFA3 is activated in the affinity order propionate $>$ butyrate $\geqslant$ acetate. ${ }^{37-39}$ However, results of studies using animal models must be noted with caution owing to interspecies variability. Hudson et al. ${ }^{40}$ reported that in mice FFA2 and FFA3 have equal affinity for acetate and butyrate, whereas FFA3 has higher affinity for propionate than FFA2.

FFA2 and FFA3 are both widely expressed throughout the small intestine and colon. ${ }^{37,41,42}$ FFA2 and FFA3 mRNA have also been discovered in areas other than the gut, which lead to the assumption that SCFAs are likely to have beneficial effects on tissues and organs beyond the gut. FFA2 mRNA has been detected in immune cells, skeletal muscle, heart, spleen and adipose tissue, ${ }^{37,42-44}$ whereas the expression of FFA3 appears to be more widespread and has been detected in adipose tissue, peripheral blood mononuclear cells, pancreas, spleen, bone marrow and lymph nodes. ${ }^{37,38,42}$ However, reports investigating the expression of both SCFA receptors in adipose tissue have proven to be inconsistent. ${ }^{37,43,45-47}$

\section{SCFAs and energy intake in animal models}

The addition of FCs to the diets of animals has been shown to reduce energy intake. ${ }^{26,27,48,49}$ Several studies have investigated the effect of FCs on feeding motivation, however, the results have been equivocal. ${ }^{50,51}$ Results from studies published by our research group have shown that FCs increase manganeseenhanced magnetic resonance imaging signals in the appetite centres of the hypothalamus, further suggesting a satiating effect. $^{52,53}$ In addition, feeding FCs, as well as SCFAs themselves, have been associated with an increase in the circulating concentrations of the anorectic gut hormones, glucagon-like peptide-1 (GLP-1) and peptide YY (PYY). ${ }^{26,27,29,48,54-59}$ GLP-1 and PYY are produced by $L$ cells, which are present throughout the gastrointestinal tract, with the highest concentrations observed in the distal ileum and colon, and are released in response to food intake. ${ }^{60,61}$ Peripheral infusions of these gut hormones have been shown to cause a reduction in energy intake and have thus become the target of many anti-obesity therapies. ${ }^{62-65}$

The discovery of the co-expression of FFA2 and FFA3 in GLP-1 and PYY releasing enteroendocrine $L$ cells has prompted suggestions that the detection of SCFAs in the colon may be responsible for triggering the release of these gut hormones. ${ }^{54,66,67}$ This theory is supported by reports that FFA3 knock-out $(K O)$ mice demonstrate an impaired PYY expression ${ }^{68}$ and that FFA2 KO mice exhibit reduced GLP-1 concentrations in vivo and in response to SCFA in vitro. ${ }^{54}$ Furthermore, FC supplementation has been shown to increase the densities of FFA2-positive enteroendocrine cells in parallel with GLP-1containing cells. ${ }^{69}$ However, it is currently unclear whether this is because of a SCFA-stimulated increase in cell proliferation or an increase in the expression of SCFA receptors in the gut epithelium.

It has recently been reported that propionate stimulates the secretion of both GLP-1 and PYY from wild type (WT) primary murine colonic crypt cultures, an effect that was significantly reduced in FFA2 KO mice cultures. ${ }^{70}$ In addition, intra-colonic infusions of propionate reportedly increased both GLP-1 and PYY levels in jugular vein plasma in vivo, an effect that was not present in FFA2 KO mice. These data further support the mounting evidence that FCs stimulate the secretion of GLP-1 and PYY. Additional evidence suggests a role for propionate in the modulated expression of FFA2, PPAR- $\gamma$ (peroxisome proliferatoractivated receptor gamma), Fiaf and histone deacetylases. ${ }^{71}$

Our research group recently investigated the role of the most abundant SCFA, acetate, in central appetite regulation in mice. ${ }^{72}$ In line with recent observations, we noted that dietary supplementation with the FC inulin causes a significant reduction in energy intake and weight gain. ${ }^{26,73}$ In addition, we investigated the effect 
of intravenous and colonic infusions of ${ }^{11} \mathrm{C}$-acetate in vivo using positron-emission tomography-computed tomography scanning and found that although the majority of ${ }^{11} \mathrm{C}$-acetate tracer was absorbed by the heart and liver, a small amount crossed the blood-brain barrier ( 3\%) and was taken up by the brain. We subsequently confirmed that acetate induces hypothalamic neuronal activation in the arcuate nucleus following intraperitoneal administration, suggesting that acetate itself is an anorectic signal.

That FCs reportedly have beneficial effects on energy homeostasis but also increase energy harvest appears counterintuitive. It has been suggested that the metabolisable energy gained from SCFAs via the colonic fermentation process of non-digestible carbohydrates may outweigh the beneficial effects associated with their consumption. Indeed, Isken et al. ${ }^{74}$ demonstrated that long-term consumption (45 weeks) of soluble guar fibre significantly increased both body weight and markers of insulin resistance in mice, when compared with controls, despite a comparable dietary energy intake in both groups. Their data provides evidence that increased SCFA production in rodents, which significantly contributes to digested energy, may outweigh the short-term beneficial effects of soluble fibre consumption. These results may be explained by research carried out by Track et $a l^{30}$, which reported that feeding adolescent rats guar gum results in a reduction in food intake and weight gain and improved glucose tolerance. However, these beneficial effects were only observed in adolescent rats, when compared with controls, and were absent in adults.

\section{FCs and energy intake in humans}

As discussed earlier, evidence suggests that hominin's diets consisted of mainly vegetable matter and would have had a large fermentable component. ${ }^{5}$ It is highly likely that this large FC consumption would therefore have stimulated gut hormone release, slowing gastric emptying and small intestinal transit. It is possible that this was advantageous as it would have increased the energy harvest from nutritionally poor food during periods when it was a major struggle for hominins to meet their energy demands. However, it is likely that this physiological adaptation is underutilised by humans in the developed world owing to wider food availability and the lower FC content of the average westerner's diet. ${ }^{15}$ Behall et al. ${ }^{75}$ suggest that the fermentation process significantly contributes to digestible energy when amounts of $>20 \mathrm{~g}$ non-digestible carbohydrates are consumed. It has been demonstrated that overweight and obese individuals have higher faecal SCFA concentrations than their lean counterparts. $^{24,76}$ The results suggest that these individuals produce more colonic SCFA, indicating an increased microbial energy harvest in obesity. ${ }^{76}$ However, in vitro fermentations using faecal samples from obese and lean individuals displayed no difference in total SCFA production. ${ }^{77}$

Although there is clear evidence from a number of small animal studies that the addition of FCs to the feed of high-fat-fed animals results in improvements in body weight and composition, $26-28$ translation to humans has proven inconsistent. This may be owing to the relatively small amount of FC used in human experimental diets compared with animal studies $(1.5 \%$ and $>5 \%$ of total energy intake, respectively). Large amounts of FCs are generally not well tolerated as they are associated with undesirable gastrointestinal effects, resulting in the use of lower doses in human research trials.

However, a number of notable acute and long-term supplementation studies have been successfully carried out in humans. Archer et al. ${ }^{78}$ reported that replacing fat with an acute dose of inulin $(24 \mathrm{~g})$ at breakfast results in lower energy and fat intake throughout the day, although gut hormone concentrations were not reported. Nilsson et al. ${ }^{79}$ demonstrated that consuming an evening meal consisting of FCs significantly increases circulating PYY concentrations and decreases ghrelin concentrations at breakfast. Our research group recently carried out a dose-finding study and demonstrated that increased circulating PYY concentrations and appetite suppression occurs only with an acute dose of $>35 \mathrm{~g}$ per day of inulin, suggesting the need for large doses in order to induce appetite suppression. ${ }^{80}$ Evidence from long-term studies suggest that supplementation (2-12 weeks) with oligofructose (16-30 g per day) significantly increases feelings of satiety and reduces feelings of hunger, reduces energy intake, increases the total area under the curve for PYY and reduces total area under the curve for ghrelin, an orexigenic hormone. ${ }^{81-83}$ A 1-year study investigating supplementation with high-wheat fibre also resulted in both an increase in SCFA production and GLP-1 secretion. ${ }^{84}$ The authors note that these changes took 9-12 months to develop, suggesting that it may take up to a year for the gut microbiota to adapt to the extra fermentable content of the diet. However, data from a recent study showed that short-term dietary change alters both the microbial community structure and gene expression of the human gut microbiome, rapidly and reproducibly. ${ }^{85}$ Thus, the optimum time period for adaptation to a high FC diet is, at the present time, unclear.

Our research group recently investigated the role of propionate in appetite regulation. We demonstrated that propionate significantly stimulates the release of PYY and GLP-1 from human colonic cells. ${ }^{86}$ Next, we produced a novel system, inulinpropionate ester, whereby propionate is conjugated by an ester linkage to inulin, a carrier molecule. The ester linkage is broken down by bacterial fermentation, which results in the delivery of propionate directly to the colon. When administered acutely, we found that inulin-propionate ester significantly increased postprandial PYY and GLP-1, and reduced energy intake by 14\% at a buffet meal. Furthermore, after a 24-week supplementation period we demonstrated that inulin-propionate ester significantly reduced weight gain in overweight adults.

Beneficial effects associated with SCFA production independent of food intake

The importance of SCFAs to energy metabolism has been further emphasised in recent studies where germ-free mice have received gut microbiota transplants. These investigations highlight that the transfer of gut microbiota compositions, which produce different levels of SCFAs in the colon, influence body weight gain and adiposity. ${ }^{87,88}$ For example, it has been shown that the transplantation of the faecal microbiota of twins discordant for obesity to germ-free mice results in a similar phenotype in the recipient mice. ${ }^{87}$ It was noted that the lean mice demonstrated significantly increased caecal propionate and butyrate contents when compared with their obese counterparts. Their data suggest that the increased weight gain observed in the obese mice was not caused by an increased energy harvest by the gut microbiota and suggests that instead, SCFAs inhibit the fat accumulation associated with obesity. Similarly, the faecal transplantation of mice that have undergone Roux-en- $Y$ gastric bypass (RYGB) surgery to germ-free mice has been shown to result in weight loss and reduced fat mass in the RYGB-recipient mice. ${ }^{88}$ In addition, the RYGB-recipient mice exhibited a relatively greater production of propionate and lower production of acetate when compared with mice that received the faecal microbiota of those that had undergone sham surgery. The beneficial change in body composition observed in RYGB-recipient mice may be owing to the beneficial effects associated with the SCFA production profile of these mice. The authors suggest that the reduced levels of acetate would result in decreased lipogenesis and that the increased levels of propionate would assist in the inhibition of acetate conversion into lipid in the liver and adipose tissue. ${ }^{43,89,90}$ The metabolic effects noted in these studies were not associated 
with any significant change in energy intake, ${ }^{87,88}$ suggesting that the positive effects on energy balance observed may be a result of a change in energy utilisation and expenditure.

A recent study carried out by Remely et al. ${ }^{91}$ demonstrated a lower methylation status in the promoter region of the FFA3 gene in the blood of both obese and type 2 diabetics, when compared with lean individuals. The researchers hypothesise that this is owing to compositional differences in the gut microbiota and therefore different SCFA profiles.

SCFAs, energy expenditure and substrate metabolism

Although the consumption of FCs and SCFAs have been associated with a reduction in energy intake, there is also evidence that SCFAs may increase energy expenditure. SCFAs have been shown to increase the rates of oxygen consumption, enhance both adaptive thermogenesis and fat oxidation and increase mitochondrial function in rodents. ${ }^{73,92}$ Marsan and McBurney ${ }^{93}$ also demonstrated that the oxidation of all three principle SCFAs was significantly higher for colonocytes isolated from rodents who had consumed a high fibre diet for 14 days. Gao et $a .^{73}$ also investigated the expression of two thermogenesisrelated genes, PGC-1a and UCP-1, and discovered that the mRNA and expression of both genes were upregulated in those whose diets were supplemented with butyrate. Furthermore, consuming a diet high in whole-grain foods has been shown to decrease urinary excretion of markers of protein catabolism which was associated with an increase in SCFA production. ${ }^{94}$ In addition, it has been demonstrated that SCFAs can be used as an energy source for protein gain when pigs are fed below their energy requirements. ${ }^{95}$

Evidence from several research studies indicates that the SCFA receptors FFA2 and FFA3 may have a critical role in energy homeostasis. It has been demonstrated that FFA3 KO mice exhibit a reduced energy expenditure, compared with WT mice, despite having matching physical activity levels. ${ }^{92,96}$ In addition, Kimura et al. ${ }^{92}$ reported that treatment with propionate increases the rate of oxygen consumption in WT mice, a result that was not present in FFA3 KO mice. SCFAs were subsequently shown to stimulate sympathetic nervous system activity directly through FFA3 at the sympathetic ganglion, thereby controlling energy expenditure. ${ }^{92}$ In addition, recent evidence suggests that propionate binds FFA3 in the periportal afferent system to induce intestinal gluconeogenesis (IGN) via a gut-brain neural circuit. ${ }^{97}$ Similarly, it has been reported that FFA2 KO mice exhibit a reduction in energy expenditure when fed a high-fat diet, compared with WT mice, and are obese despite a similar physical activity level. ${ }^{98}$ In contrast, mice with adipose-specific overexpression of FFA2 exhibited an increase in energy expenditure. Interestingly, the FFA2 KO mice had a higher RER than WT mice, which suggests a reduced capacity to oxidise fat, whereas mice with adipose-specific overexpression of FFA2 had a lower RER than WT mice. The authors note that their results indicate that FFA2 activation increases energy expenditure and the capacity to oxidise fats via the suppression of fat accumulation and adipose tissue insulin signalling.

Research suggests that SCFAs and their receptors, FFA2 and FFA3, may have a critical role in maintaining energy homeostasis. However, there is currently no known study that has specifically investigated the effect of FC consumption on energy expenditure in humans and would make for an interesting line of investigation.

\section{SCFAs and hepatic metabolism}

There is evidence that feeding rodents a diet supplemented with FCs or SCFAs results in reduced intrahepatocellular lipid levels, liver triglyceride and cholesterol content, hepatic cholesterol synthesis and hepatic glucose production. ${ }^{52,53,97,99-101}$ SCFAs are absorbed from the intestinal lumen into the portal vein and subsequently enter the hepatic blood flow. As butyrate is the preferred fuel for colonocytes, the majority of butyrate produced in the gut is rapidly utilised at the epithelium. ${ }^{18,102}$ In contrast, the majority of propionate and acetate produced in the gut is absorbed and drains into the portal vein. ${ }^{103}$ Cummings et al. ${ }^{18}$ investigated SCFA distribution in sudden death victims and demonstrated that the majority of butyrate and propionate present in the portal vein is extracted by the liver and subsequently metabolised (86 and 94\%, respectively), with a small amount of remaining propionate and butyrate entering venous blood. Bloemen et al. ${ }^{102}$ reported that liver uptake of acetate was not significant. These results may suggest that any hepatic changes associated with FC consumption or SCFA administration are largely because of the metabolism of propionate by the liver. It is known that propionate is a gluconeogenic substrate and inhibits the utilisation of acetate for lipid and cholesterol synthesis. ${ }^{89,104}$ Therefore, potential upregulation of this pathway after FC consumption is likely to be responsible for any observed changes in hepatic structure or function.

A number of studies have reported that FC consumption in humans beneficially affects serum cholesterol and triglyceride concentrations, and reduces hepatic lipogenesis. ${ }^{31,35,105-107}$ In addition, our research group recently demonstrated a significant reduction in the intrahepatocellular lipid levels of overweight adults meeting the criteria for non-alcoholic fatty liver disease after a 24-week increase in colonic propionate concentrations. $^{86}$ Furthermore, SCFAs may have an indirect benefit on hepatic metabolism through their effect on gut hormone secretion. In particular, GLP-1 has been shown to modulate physiological mechanisms responsible for free fatty acid accumulation in the liver and reduce hepatic steatosis. ${ }^{108}$

\section{SCFAs, glucose uptake and gluconeogenesis}

The consumption of FCs has been associated with an improvement in glucose homeostasis, although the evidence in humans is inconsistent. Propionate is gluconeogenic and has been shown to produce a dose-dependent increase in blood glucose concentrations in humans. ${ }^{89,104,109}$ Again, the notion that FC consumption may have beneficial effects on glucose homeostasis appears paradoxical. However, it has been demonstrated that SCFAs have no significant effect on glucose metabolism in healthy men. ${ }^{110}$ In addition, it has been shown that propionate-supplementation induces a reduction in fasting blood glucose in rats. ${ }^{111}$

The intestine has recently been established as a gluconeogenic organ and it has been reported that IGN promotes metabolic benefits and regulates energy and glucose homeostasis. ${ }^{112,113}$ Delaere et al. ${ }^{114}$ later demonstrated that a portal vein glucose sensor is activated by IGN and transmits signals to the brain via the peripheral nervous system, which initiates these beneficial effects. It has been reported that both propionate and butyrate stimulate IGN. ${ }^{97}$ Although butyrate was found to directly activate the expression of IGN genes in enterocytes, propionate itself was shown to act as a substrate for IGN. In addition, rats fed a SCFA- or a FCsupplemented diet displayed a significantly lower weight gain, reduced adiposity, improved glucose control and reduced hepatic glucose production when compared with the control group. It was noted that this improvement in glucose tolerance involved both gutbrain communication and IGN, and that none of the reported metabolic benefits were present in mice lacking the catalytic subunit of a key enzyme involved in IGN, intestinal glucose-6-phosphatase, despite a similar shift in the gut microbiota composition. These data suggest that IGN has a major role in mediating the beneficial effects associated with the consumption of FCs. 


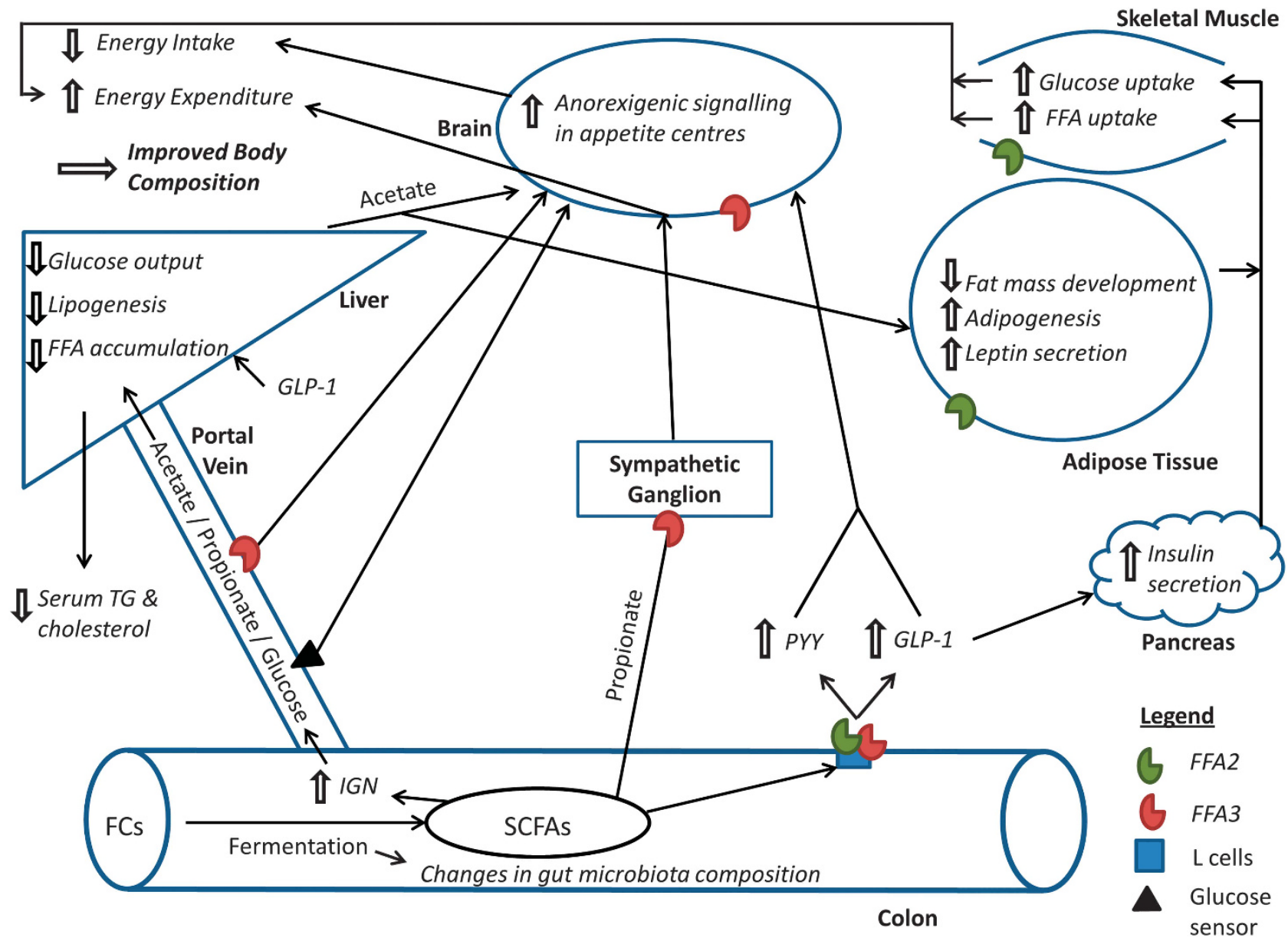

Figure 2. An overarching model for the beneficial effects of colonic SCFA production on appetite regulation and energy homeostasis. FCs, fermentable carbohydrates; FFA, free fatty acids; FFA2, free fatty acid receptor 2; FFA3, free fatty acid receptor 3; GLP-1, glucagon like peptide-1; IGN, intestinal gluconeogenesis; PYY, peptide YY; SCFAs, short chain fatty acids; TG, triglyceride.

\section{SCFAs and adipocytes}

It has been observed that FC consumption protects against fat mass development. ${ }^{26-28}$ All three principle SCFAs have also been shown to protect against diet-induced obesity. ${ }^{55}$

A number of studies have reported that treatment with the SCFAs, propionate and acetate increases the expression of leptin, a potent anorectic hormone, in adipocytes in vitro, whereas butyrate has been shown to have no effect. ${ }^{43,45,46}$ In addition, propionate has been shown to increase plasma leptin concentrations in mice in vivo ${ }^{45}$ and stimulate mRNA expression in human adipose tissue. ${ }^{115}$ Xiong et al. ${ }^{45}$ reported that this SCFA-stimulated increase in leptin expression in adipocytes is mediated by FFA3. However, not all reports regarding the body composition of FFA3 KO mice have been consistent. ${ }^{55,68,96}$ Furthermore, a number of contradictory reports suggesting that the expression of FFA3 cannot be detected in adipose tissue have been published, indicating that the SCFA-stimulated increase in leptin expression is not mediated by FFA3. ${ }^{43,46}$ Zaibi et al. ${ }^{46}$ suggest that the SCFA-stimulated increase in leptin expression is mediated by FFA2 and that the downregulation of FFA2 in FFA3 KO mice is responsible for the reduction in SCFA-stimulated leptin secretion observed in FFA3 $\mathrm{KO}$ mice. However, Frost et al. ${ }^{47}$ failed to demonstrate a significant effect of SCFAs on leptin secretion in adipocytes.

Kimura et al. ${ }^{98}$ recently demonstrated that SCFA-mediated activation of FFA2 suppresses insulin signalling within adipocytes, which results in the inhibition of fat accumulation within adipose tissue and the promotion of metabolism of unincorporated glucose and lipids in other tissues. In addition, it was reported that FFA2 KO mice were obese on a normal diet, which was further enhanced by a high-fat diet, that adipose-specific FFA2 transgenic mice had a significantly lower body weight than WT mice and that mice overexpressing FFA2 in their adipose tissue remained lean even when consuming a high-fat diet. The researchers suggest that FFA2 may act as a sensor for excessive dietary energy, controlling energy utilisation and maintaining metabolic homeostasis. However, these observations are not supported by Bjursell et al. ${ }^{116}$ who reported that FFA2-deficient mice consuming a highfat diet exhibit a reduction in body-fat mass and increase in lean body mass. In addition, it has been shown that all three principle SCFAs enhance the degree of adipocyte differentiation ${ }^{43,117}$ and that propionate and acetate inhibit lipolysis. ${ }^{43}$ Hong et $a .^{43}$ also demonstrated that propionate increases the expression of FFA2 during adipocyte differentiation and causes an upregulation of PPAR- $\gamma 2$. The authors suggest that these results indicate the involvement of FFA2 in the lipid accumulation pathway. This is further supported by Ge et al. ${ }^{118}$ who reported that acetate and propionate inhibit adipose tissue lipolysis in a mouse model via FFA2 resulting in a reduction in plasma free fatty acid concentrations. Hosseini et al. ${ }^{119}$ demonstrated that propionate increased the gene expression of adiponectic receptors 1 and 2 in the adiponectin system.

It has also been suggested that FFA3 may have a role in insulinstimulated glucose uptake. Han et al. ${ }^{120}$ reported that propionate 
and valerate enhance insulin-stimulated glucose uptake in adipocytes which appeared to be mediated via FFA3.

Although data from animal studies suggest that SCFAs and the activity of their receptors, FFA2 and FFA3, may have an inhibitory effect against weight gain, there is currently a lack of evidence to support this hypothesis in humans. As acetate and propionate are the most potent activators of FFA2 it seems likely that these SCFAs are responsible for any adipocyte-related changes observed after FC consumption or SCFA administration. However, as acetate circulates at a higher concentration than both butyrate and propionate, it seems the most likely SCFA to directly influence

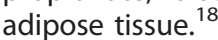

\section{CONCLUSION}

A significant body of evidence suggests that SCFAs have a beneficial role in appetite and energy homeostasis. However, as the majority of research comes from animal models, caution when translating this evidence to humans is necessary. Thus, there is an urgent need for human data to support the mechanistic data being reported. One major issue is that large amounts of FCs are generally not tolerated well by humans, which results in a relatively small amount of FCs being used in human experimental diets when compared with animal studies. Therefore, effective strategies that replicate the changes in SCFA profiles seen in animal studies, either via dietary or pharmacological means, may have the potential to translate the beneficial effects observed in animal studies to man.

In conclusion, it is evident that the administration of FCs and their breakdown products, SCFAs, have positive effects on host physiology. However, the majority of recent publications have investigated the effect of SCFAs on one particular tissue or metabolic process and have failed to look at the body system as a whole. Here, we propose that SCFAs have a number of metabolic processes, which are activated in parallel, that affect energy homeostasis and appetite regulation (summarised in Figure 2). Furthermore, the site-specific uptake of SCFA across the gut-liver-peripheral tissue axis suggests selectivity in the effect of individual SCFA. It is only by bringing these effects together that the true impact of SCFAs on host energy homeostasis can be seen.

\section{CONFLICT OF INTEREST}

The authors declare no conflict of interest.

\section{ACKNOWLEDGEMENTS}

The Section (Investigative Medicine) at Imperial College is funded by grants from the MRC, BBSRC, NIHR, an Integrative Mammalian Biology (IMB) Capacity Building Award, a FP7- HEALTH- 2009- 241592 EurOCHIP grant and is supported by the NIHR Imperial Biomedical Research Centre Funding Scheme. GF is supported by an NIHR senior investigator award, CSB is supported by an MRC Case Studentship, ESC is supported by the BBSRC. All authors contributed to the writing of this manuscript.

\section{REFERENCES}

1 Swinburn BA, Sacks G, Hall KD, McPherson K, Finegood DT, Moodie ML et al. The global obesity pandemic: shaped by global drivers and local environments. Lancet 2011; 378: 804-814.

2 Eaton SB, Konner M. Paleolithic nutrition: a consideration of its nature and current implications. N Engl J Med 1985; 312: 283-289.

3 Popkin BM, Adair LS, Ng SW. Global nutrition transition and the pandemic of obesity in developing countries. Nutr Rev 2012; 70: 3-21.

4 Prentice AM, Jebb SA. Fast foods, energy density and obesity: a possible mechanistic link. Obes Rev 2003; 4: 187-194.

5 Eaton SB. The ancestral human diet: what was it and should it be a paradigm for contemporary nutrition? Proc Nutr Soc 2006; 65: 1-6.

6 Whitton C, Nicholson SK, Roberts C, Prynne CJ, Pot GK, Olson A et al. National diet and nutrition survey: UK food consumption and nutrient intakes from the first year of the rolling programme and comparisons with previous surveys. $\mathrm{Br} J$ Nutr 2011; 106: 1899-1914.

7 Bäckhed F. Host responses to the human microbiome. Nutr Rev 2012; 70 S14-S17.

8 Neish AS. Microbes in gastrointestinal health and disease. Gastroenterology 2009; 136: 65-80.

9 Bäckhed F, Ding H, Wang T, Hooper LV, Koh GY, Nagy A et al. The gut microbiota as an environmental factor that regulates fat storage. Proc Natl Acad Sci USA 2004; 101: 15718-15723.

10 Turnbaugh PJ, Ley RE, Mahowald MA, Magrini V, Mardis ER, Gordon J. An obesity-associated gut microbiome with increased capacity for energy harvest. Nature 2006; 444: 1027-1131.

11 Holmes E, Li JV, Marchesi JR, Nicholson JK. Gut microbiota composition and activity in relation to host metabolic phenotype and disease risk. Cell Metab 2012; 16: 559-564.

12 Lunn J, Buttriss J. Carbohydrates and dietary fibre. Nutr Bull 2007; 32: 21-64.

13 James S, Muir J, Curtis S, Gibson P. Dietary fibre: a roughage guide. Intern Med J 2003; 33: 291-296.

14 Wong JM, de Souza R, Kendall CW, Emam A, Jenkins DJ. Colonic health: fermentation and short chain fatty acids. J Clin Gastroenterol 2006; 40: 235-243.

15 Popovich DG, Jenkins DJ, Kendall CW, Dierenfeld ES, Carroll RW, Tariq N et al. The western lowland gorilla diet has implications for the health of humans and other hominoids. J Nutr 1997; 127: 2000-2005.

16 Frost GS, Walton GE, Swann JR, Psichas A, Costabile A, Johnson LP et al. Impacts of plant-based foods in ancestral hominin diets on the metabolism and function of gut microbiota in vitro. MBio 2014; 5: e00853-14.

$17 \mathrm{McNeil} N$. The contribution of the large intestine to energy supplies in man. Am J Clin Nutr 1984; 39: 338-342.

18 Cummings J, Pomare E, Branch W, Naylor C, Macfarlane G. Short chain fatty acids in human large intestine, portal, hepatic and venous blood. Gut 1987; 28: 1221-1227.

19 Berggren AM, Björck IM, Nyman E, Eggum BO. Short-chain fatty acid content and $\mathrm{pH}$ in caecum of rats given various sources of carbohydrates. J Sci Food Agri 1993; 63: 397-406.

20 Levrat M-A, Rémésy $C$, Demigné $C$. High propionic acid fermentations and mineral accumulation in the cecum of rats adapted to different levels of inulin. $J$ Nutr 1991; 121: 1730-1737.

21 Brinkworth GD, Noakes M, Clifton PM, Bird AR. Comparative effects of very low-carbohydrate, high-fat and high-carbohydrate, low-fat weight-loss diets on bowel habit and faecal short-chain fatty acids and bacterial populations. Br J Nutr 2009; 101: 1493-1502.

22 Wisker E, Maltz A, Feldheim W. Metabolisable energy of diets low or high in dietary fiber from cereals when eaten by humans. J Nutr 1988; 118 945-952.

23 Peng X, Li S, Luo J, Wu X, Liu L. Effects of dietary fibers and their mixtures on short chain fatty acids and microbiota in mice guts. Food Funct 2013; 4: 932-938.

24 Schwiertz A, Taras D, Schäfer K, Beijer S, Bos NA, Donus C et al. Microbiota and SCFA in lean and overweight healthy subjects. Obesity 2010; 18: 190-195.

25 Murphy E, Cotter P, Healy S, Marques T, O'Sullivan O, Fouhy F et al. Composition and energy harvesting capacity of the gut microbiota: relationship to diet, obesity and time in mouse models. Gut 2010; 59: 1635-1642.

26 Cani PD, Neyrinck AM, Maton N, Delzenne NM. Oligofructose promotes satiety in rats fed a high-fat diet: involvement of glucagon-like peptide-1. Obes Res 2005 13: 1000-1007.

27 Delmée E, Cani PD, Gual G, Knauf C, Burcelin R, Maton N et al. Relation between colonic proglucagon expression and metabolic response to oligofructose in high fat diet-fed mice. Life Sci 2006; 79: 1007-1013.

28 Arora T, Loo RL, Anastasovska J, Gibson GR, Tuohy KM, Sharma RK et al. Differential effects of two fermentable carbohydrates on central appetite regulation and body composition. PLoS One 2012; 7: e43263.

29 Reimer RA, Maurer AD, Eller LK, Hallam MC, Shaykhutdinov R, Vogel HJ et al. Satiety hormone and metabolomic response to an intermittent high energy diet differs in rats consuming long-term diets high in protein or prebiotic fiber. J Proteome Res 2012; 11: 4065-4074.

30 Track NS, Cawkwell ME, Chin BC, Chiu SS, Haberer SA, Honey CR. Guar gum consumption in adolescent and adult rats: short-and long-term metabolic effects. Can J Physiol Pharmacol 1985; 63: 1113-1121.

31 Bourdon I, Yokoyama W, Davis P, Hudson C, Backus R, Richter D et al. Postprandial lipid, glucose, insulin, and cholecystokinin responses in men fed barley pasta enriched with $\beta$-glucan. Am J Clin Nutr 1999; 69: 55-63.

32 Bays $\mathrm{H}$, Frestedt JL, Bell M, Williams C, Kolberg L, Schmelzer W et al. Reduced viscosity Barley b-Glucan versus placebo: a randomized controlled trial of the effects on insulin sensitivity for individuals at risk for diabetes mellitus. Nutr Metab (Lond) 2011; 8: 58. 
33 Behall KM, Scholfield DJ, Hallfrisch JG. Barley $\beta$-glucan reduces plasma glucose and insulin responses compared with resistant starch in men. Nutr Res 2006; 26 : 644-650.

34 Vogt JA, Ishii-Schrade KB, Pencharz PB, Jones PJ, Wolever TM. L-rhamnose and lactulose decrease serum triacylglycerols and their rates of synthesis, but do not affect serum cholesterol concentrations in men. J Nutr 2006; 136: 2160-2166.

35 Letexier D, Diraison F, Beylot M. Addition of inulin to a moderately highcarbohydrate diet reduces hepatic lipogenesis and plasma triacylglycerol concentrations in humans. Am J Clin Nutr 2003; 77: 559-564.

36 Van Dokkum W, Wezendonk B, Srikumar T, Van den Heuvel E. Effect of nondigestible oligosaccharides on large-bowel functions, blood lipid concentrations and glucose absorption in young healthy male subjects. Eur J Clin Nutr 1999; 53: $1-7$.

37 Brown AJ, Goldsworthy SM, Barnes AA, Eilert MM, Tcheang L, Daniels D et al. The orphan G protein-coupled receptors GPR41 and GPR43 are activated by propionate and other short chain carboxylic acids. J Biol Chem 2003; 278: 11312-11319.

38 Le Poul E, Loison C, Struyf S, Springael J-Y, Lannoy V, Decobecq M-E et al. Functional characterization of human receptors for short chain fatty acids and their role in polymorphonuclear cell activation. J Biol Chem 2003; 278: 25481-25489.

39 Nilsson NE, Kotarsky K, Owman C, Olde B. Identification of a free fatty acid receptor, FFA $2 \mathrm{R}$, expressed on leukocytes and activated by short-chain fatty acids. Biochem Biophys Res Commun 2003; 303: 1047-1052.

40 Hudson BD, Tikhonova IG, Pandey SK, Ulven T, Milligan G. Extracellular ionic locks determine variation in constitutive activity and ligand potency between species orthologs of the free fatty acid receptors FFA2 and FFA3. J Biol Chem 2012; 287: 41195-41209.

41 Nøhr MK, Pedersen MH, Gille A, Egerod KL, Engelstoft MS, Husted AS et al. GPR41/FFAR3 and GPR43/FFAR2 as cosensors for short-chain fatty acids in enteroendocrine cells vs FFAR3 in enteric neurons and FFAR2 in enteric leukocytes. Endocrinology 2013; 154: 3552-3564.

42 Li G, Su H, Zhou Z, Yao W. Identification of the porcine G protein-coupled receptor 41 and 43 genes and their expression pattern in different tissues and development stages. PLoS One 2014; 9: e97342.

43 Hong Y-H, Nishimura Y, Hishikawa D, Tsuzuki H, Miyahara H, Gotoh C et al. Acetate and propionate short chain fatty acids stimulate adipogenesis via GPCR43. Endocrinology 2005; 146: 5092-5099.

44 Masui R, Sasaki M, Funaki Y, Ogasawara N, Mizuno M, lida A et al. G proteincoupled receptor 43 moderates gut inflammation through cytokine regulation from mononuclear cells. Inflamm Bowel Dis 2013; 19: 2848-2856.

45 Xiong Y, Miyamoto N, Shibata K, Valasek MA, Motoike T, Kedzierski RM et al. Short-chain fatty acids stimulate leptin production in adipocytes through the G protein-coupled receptor GPR41. Proc Natl Acad Sci USA 2004; 101: 1045-1050.

46 Zaibi MS, Stocker CJ, O'Dowd J, Davies A, Bellahcene M, Cawthorne MA et al. Roles of GPR41 and GPR43 in leptin secretory responses of murine adipocytes to short chain fatty acids. FEBS Lett 2010; 584: 2381-2386.

47 Frost G, Cai Z, Raven M, Otway D, Mushtaq R, Johnston J. Effect of short chain fatty acids on the expression of free fatty acid receptor 2 (Ffar2), Ffar3 and earlystage adipogenesis. Nutr Diabetes 2014; 4: e128.

48 Cani PD, Dewever C, Delzenne NM. Inulin-type fructans modulate gastrointestinal peptides involved in appetite regulation (glucagon-like peptide-1 and ghrelin) in rats. Br J Nutr 2004; 92: 521-526.

49 Delzenne NM, Cani PD, Daubioul C, Neyrinck AM. Impact of inulin and oligofructose on gastrointestinal peptides. Br J Nutr 2005; 93: S157-S161.

50 Jensen MB, Pedersen LJ, Theil PK, Yde CC, Knudsen KB. Feeding motivation and plasma metabolites in pregnant sows fed diets rich in dietary fiber either once or twice daily. J Anim Sci 2012; 90: 1910-1919.

51 Souza da Silva C, Bolhuis JE, Gerrits WJ, Kemp B, van den Borne JJ. Effects of dietary fibers with different fermentation characteristics on feeding motivation in adult female pigs. Physiol Behav 2013; 110: 148-157.

52 Anastasovska J, Arora T, Canon GJS, Parkinson JR, Touhy K, Gibson GR et al. Fermentable carbohydrate alters hypothalamic neuronal activity and protects against the obesogenic environment. Obesity 2012; 20: 1016-1023.

53 So P-W, Yu W-S, Kuo Y-T, Wasserfall C, Goldstone AP, Bell JD et al. Impact of resistant starch on body fat patterning and central appetite regulation. PLoS One 2007; 2: e1309.

54 Tolhurst G, Heffron H, Lam YS, Parker HE, Habib AM, Diakogiannaki E et al. Shortchain fatty acids stimulate glucagon-like peptide- 1 secretion via the G-proteincoupled receptor FFAR2. Diabetes 2012; 61: 364-371.

55 Lin HV, Frassetto A, Kowalik EJ Jr, Nawrocki AR, Lu MM, Kosinski JR et al. Butyrate and propionate protect against diet-induced obesity and regulate gut hormones via free fatty acid receptor 3-independent mechanisms. PLoS One 2012; 7: e35240.
56 Cherbut C, Ferrier L, Rozé C, Anini Y, Blottière H, Lecannu G et al. Short-chain fatty acids modify colonic motility through nerves and polypeptide $Y Y$ release in the rat. Am J Physiol 1998; 275: G1415-G1422.

57 Delzenne NM, Daubioul C, Neyrinck A, Lasa M, Taper H. Inulin and oligofructose modulate lipid metabolism in animals: review of biochemical events and future prospects. Br J Nutr 2002; 87: S255-S259.

58 Zhou J, Martin RJ, Tulley RT, Raggio AM, McCutcheon KL, Shen L et al. Dietary resistant starch upregulates total GLP-1 and PYY in a sustained day-long manner through fermentation in rodents. Am J Physiol Endocrinol Metab 2008; 295: E1160.

59 Keenan MJ, Zhou J, McCutcheon KL, Raggio AM, Bateman HG, Todd E et al. Effects of resistant starch, a non-digestible fermentable fiber, on reducing body fat. Obesity 2006; 14: 1523-1534.

60 Böttcher G, Sjölund K, Ekblad E, Håkanson R, Schwartz T, Sundler F. Coexistence of peptide $\mathrm{YY}$ and glicentin immunoreactivity in endocrine cells of the gut. Regul Pept 1984; 8: 261-266.

$61 \mathrm{Ku} \mathrm{S}$, Lee $\mathrm{H}$, Lee J. An immunohistochemical study of the gastrointestinal endocrine cells in the C57BL/6 mice. Anat Histol Embryol 2003; 32: 21-28.

62 Flint A, Raben A, Astrup A, Holst JJ. Glucagon-like peptide 1 promotes satiety and suppresses energy intake in humans. J Clin Invest 1998; 101: 515.

63 Flint A, Raben A, Ersbøll A, Holst J, Astrup A. The effect of physiological levels of glucagon-like peptide-1 on appetite, gastric emptying, energy and substrate metabolism in obesity. Int J Obes Relat Metab Disord 2001; 25: 781-792.

64 Chelikani PK, Haver AC, Reidelberger RD. Intravenous infusion of peptide YY (3-36) potently inhibits food intake in rats. Endocrinology 2005; 146: 879-888.

65 Pittner R, Moore C, Bhavsar S, Gedulin B, Smith P, Jodka C et al. Effects of PYY; 3-36; in rodent models of diabetes and obesity. Int $J$ Obes Relat Metab Disord 2004; 28: 963-971.

66 Karaki S-i, Mitsui R, Hayashi H, Kato I, Sugiya H, Iwanaga T et al. Short-chain fatty acid receptor, GPR43, is expressed by enteroendocrine cells and mucosal mast cells in rat intestine. Cell Tissue Res 2006; 324: 353-360.

67 Karaki S-i, Tazoe H, Hayashi H, Kashiwabara H, Tooyama K, Suzuki Y et al. Expression of the short-chain fatty acid receptor, GPR43, in the human colon. $J$ Mol Histol 2008; 39: 135-142.

68 Samuel BS, Shaito A, Motoike T, Rey FE, Backhed F, Manchester JK et al. Effects of the gut microbiota on host adiposity are modulated by the short-chain fatty-acid binding G protein-coupled receptor, Gpr41. Proc Natl Acad Sci USA 2008; 105: 16767-16772.

69 Kaji I, Karaki S-i, Tanaka R, Kuwahara A. Density distribution of free fatty acid receptor 2 (FFA2)-expressing and GLP-1-producing enteroendocrine $L$ cells in human and rat lower intestine, and increased cell numbers after ingestion of fructo-oligosaccharide. J Mol Histol 2011; 42: 27-38.

70 Psichas A, Sleeth M, Murphy K, Brooks L, Bewick G, Hanyaloglu A et al. The short chain fatty acid propionate stimulates GLP-1 and PYY secretion via free fatty acid receptor 2 in rodents. Int J Obes (Lond) 2015; 39: 424-429.

71 Lukovac S, Belzer C, Pellis L, Keijser BJ, de Vos WM, Montijn RC et al. Differential modulation by Akkermansia muciniphila and Faecalibacterium prausnitzii of host peripheral lipid metabolism and histone acetylation in mouse gut organoids. MBio 2014; 5: e01438-14.

72 Frost G, Sleeth ML, Sahuri-Arisoylu M, Lizarbe B, Cerdan S, Brody L et al. The short-chain fatty acid acetate reduces appetite via a central homeostatic mechanism. Nat Commun 2014; 5: 3611.

73 Gao Z, Yin J, Zhang J, Ward RE, Martin RJ, Lefevre M et al. Butyrate improves insulin sensitivity and increases energy expenditure in mice. Diabetes 2009; 58: 1509-1517.

74 Isken F, Klaus S, Osterhoff M, Pfeiffer AF, Weickert MO. Effects of long-term soluble vs. insoluble dietary fiber intake on high-fat diet-induced obesity in C57BL/6J mice. J Nutr Biochem 2010; 21: 278-284.

75 Behall KM, Howe JC. Contribution of fiber and resistant starch to metabolisable energy. Am J Clin Nutr 1995; 62: 1158S-1160S.

76 Tremaroli V, Bäckhed F. Functional interactions between the gut microbiota and host metabolism. Nature 2012; 489: 242-249.

77 Yang J, Keshavarzian A, Rose DJ. Impact of dietary fiber fermentation from cereal grains on metabolite production by the fecal microbiota from normal weight and obese individuals. J Med Food 2013; 16: 862-867.

78 Archer BJ, Johnson SK, Devereux HM, Baxter AL. Effect of fat replacement by inulin or lupin-kernel fibre on sausage patty acceptability, post-meal perceptions of satiety and food intake in men. Br J Nutr 2004; 91: 591-599.

79 Nilsson A, Johansson E, Ekström L, Björck I. Effects of a brown beans evening meal on metabolic risk markers and appetite regulating hormones at a subsequent standardized breakfast: a randomized cross-over study. PLoS One 2013; 8: e59985.

80 Pedersen C, Lefevre S, Peters V, Patterson M, Ghatei MA, Morgan LM et al. Gut hormone release and appetite regulation in healthy non-obese participants following oligofructose intake. A dose-escalation study. Appetite 2013; 66: 44-53. 
81 Cani PD, Joly E, Horsmans Y, Delzenne NM. Oligofructose promotes satiety in healthy human: a pilot study. Eur J Clin Nutr 2006; 60: 567-572.

82 Parnell JA, Reimer RA. Weight loss during oligofructose supplementation is associated with decreased ghrelin and increased peptide $Y Y$ in overweight and obese adults. Am J Clin Nutr 2009; 89: 1751-1759.

83 Daud NM, Ismail NA, Thomas EL, Fitzpatrick JA, Bell JD, Swann JR et al. The impact of oligofructose on stimulation of gut hormones, appetite regulation, and adiposity. Obesity 2014; 22: 1430-1438.

84 Freeland KR, Wilson C, Wolever T. Adaptation of colonic fermentation and glucagon-like peptide-1 secretion with increased wheat fibre intake for 1 year in hyperinsulinaemic human subjects. Br J Nutr 2010; 103: 82-90.

85 David LA, Maurice CF, Carmody RN, Gootenberg DB, Button JE, Wolfe BE et al. Diet rapidly and reproducibly alters the human gut microbiome. Nature 2013, 505: 559-563.

86 Chambers ES, Viardot A, Psichas A, Morrison DJ, Murphy KG, Zac-Varghese SE et al. Effects of targeted delivery of propionate to the human colon on appetite regulation, body weight maintenance and adiposity in overweight adults. Gut 2014. doi: 10.1136/gutjnl-2014-307913 (E-pub ahead of print).

87 Ridaura VK, Faith JJ, Rey FE, Cheng J, Duncan AE, Kau AL et al. Gut microbiota from twins discordant for obesity modulate metabolism in mice. Science 2013 341: 1241214

88 Liou AP, Paziuk M, Luevano J-M, Machineni S, Turnbaugh PJ, Kaplan LM. Conserved shifts in the gut microbiota due to gastric bypass reduce host weight and adiposity. Sci Transl Med 2013; 5: 178ra41.

89 Wolever T, Spadafora $\mathrm{P}$, Eshuis $\mathrm{H}$. Interaction between colonic acetate and propionate in humans. Am J Clin Nutr 1991; 53: 681-687.

90 Reshef L, Niv J, Shapiro B. Effect of propionate on lipogenesis in adipose tissue. Lipid Res 1967; 8: 682-687.

91 Remely M, Aumueller E, Merold C, Dworzak S, Hippe B, Zanner J et al. Effects of short chain fatty acid producing bacteria on epigenetic regulation of FFAR3 in type 2 diabetes and obesity. Gene 2014; 537: 85-92.

92 Kimura I, Inoue D, Maeda T, Hara T, Ichimura A, Miyauchi S et al. Short-chain fatty acids and ketones directly regulate sympathetic nervous system via $G$ proteincoupled receptor 41 (GPR41). Proc Natl Acad Sci USA 2011; 108: 8030-8035.

93 Marsman KE, McBurney MI. Dietary fiber increases oxidative metabolism in colonocytes but not in distal small intestinal enterocytes isolated from rats. J Nutr 1995; 125: 273-282.

94 Ross AB, Pere-Trépat E, Montoliu I, Martin F-PJ, Collino S, Moco S et al. A wholegrain-rich diet reduces urinary excretion of markers of protein catabolism and gut microbiota metabolism in healthy men after one week. J Nutr 2013; 143: 766-773.

95 Jørgensen $\mathrm{H}$, Larsen $\mathrm{T}$, Zhao X-Q, Eggum BO. The energy value of short-chain fatty acids infused into the caecum of pigs. Br J Nutr 1997; 77: 745-756.

96 Bellahcene M, O'Dowd JF, Wargent ET, Zaibi MS, Hislop DC, Ngala RA et al. Male mice that lack the G-protein-coupled receptor GPR41 have low energy expenditure and increased body fat content. Br J Nutr 2013; 109: 1755-1764.

97 De Vadder F, Kovatcheva-Datchary P, Goncalves D, Vinera J, Zitoun C, Duchampt A et al. Microbiota-generated metabolites promote metabolic benefits via gutbrain neural circuits. Cell 2014; 156: 84-96.

98 Kimura I, Ozawa K, Inoue D, Imamura T, Kimura K, Maeda T et al. The gut microbiota suppresses insulin-mediated fat accumulation via the short-chain fatty acid receptor GPR43. Nat Commun 2013; 4: 1829.

99 Jakobsdottir G, Xu J, Molin G, Ahrné S, Nyman M. High-fat diet reduces the formation of butyrate, but increases succinate, inflammation, liver fat and cholesterol in rats, while dietary fibre counteracts these effects. PLoS One 2013; 8 e80476.

100 Hara H, Haga S, Aoyama Y, Kiriyama S. Short-chain fatty acids suppress cholesterol synthesis in rat liver and intestine. J Nutr 1999; 129: 942-948.

101 Berggren AM, Nyman E, Lundquist I, Björck IM. Influence of orally and rectally administered propionate on cholesterol and glucose metabolism in obese rats. Br J Nutr 1996; 76: 287-294.

102 Bloemen JG, Venema K, van de Poll MC, Olde Damink SW, Buurman WA, Dejong $\mathrm{CH}$. Short chain fatty acids exchange across the gut and liver in humans measured at surgery. Clin Nutr 2009; 28: 657-661.
103 Al-Lahham SaH, Peppelenbosch MP, Roelofsen H, Vonk RJ, Venema K. Biological effects of propionic acid in humans; metabolism, potential applications and underlying mechanisms. Biochim Biophys Acta 2010; 1801: 1175-1183.

104 den Besten G, Lange K, Havinga R, van Dijk TH, Gerding A, van Eunen K et al. Gutderived short-chain fatty acids are vividly assimilated into host carbohydrates and lipids. Am J Physiol Gastrointest Liver Physiol 2013; 305: G900-G910.

105 Anderson JW, Story L, Sieling B, Chen W, Petro MS, Story J. Hypocholesterolemic effects of oat-bran or bean intake for hypercholesterolemic men. Am J Clin Nutr 1984; 40: 1146-1155.

106 Talati R, Baker WL, Pabilonia MS, White CM, Coleman Cl. The effects of barleyderived soluble fiber on serum lipids. Ann Fam Med 2009; 7: 157-163.

107 Gerhardt AL, Gallo NB. Full-fat rice bran and oat bran similarly reduce hypercholesterolemia in humans. J Nutr 1998; 128: 865-869.

108 Mells JE, Anania FA. The role of gastrointestinal hormones in hepatic lipid metabolism. Semin Liver Dis 2013; 33: 343-357.

109 Jin ES, Szuszkiewicz-Garcia M, Browning JD, Baxter JD, Abate N, Malloy CR. Influence of liver triglycerides on suppression of glucose production by insulin in men. J Clin Endocrinol Metab 2014; 100: 235-243.

110 Alamowitch C, Boillot J, Boussairi A, Ruskone-Fourmestraux A, Chevalier A Rizkalla $\mathrm{S}$ et al. Lack of effect of an acute ileal perfusion of short-chain fatty acids on glucose metabolism in healthy men. Am J Physiol 1996; 271(1 Pt 1): E199-E204.

111 Boillot J, Alamowitch C, Berger A-M, Luo J, Bruzzo F, Bornet FR et al. Effects of dietary propionate on hepatic glucose production, whole-body glucose utilisation, carbohydrate and lipid metabolism in normal rats. Br J Nutr 1995; 73: 241-251.

112 Mithieux $G$. The new functions of the gut in the control of glucose homeostasis. Curr Opin Clin Nutr Metab Care 2005; 8: 445-449.

113 Troy S, Soty M, Ribeiro L, Laval L, Migrenne S, Fioramonti X et al. Intestinal gluconeogenesis is a key factor for early metabolic changes after gastric bypass but not after gastric lap-band in mice. Cell Metab 2008; 8: 201-211.

114 Delaere F, Duchampt A, Mounien L, Seyer P, Duraffourd C, Zitoun C et al. The role of sodium-coupled glucose co-transporter 3 in the satiety effect of portal glucose sensing. Mol Metab 2013; 2: 47-53.

115 Al-Lahham SaH, Roelofsen H, Priebe M, Weening D, Dijkstra M, Hoek A et al. Regulation of adipokine production in human adipose tissue by propionic acid. Eur J Clin Invest 2010; 40: 401-407.

116 Bjursell M, Admyre T, Göransson M, Marley AE, Smith DM, Oscarsson J et al. Improved glucose control and reduced body fat mass in free fatty acid receptor 2-deficient mice fed a high-fat diet. Am J Physiol Endocrinol Metab 2011; 300: E211-E220.

117 Li G, Yao W, Jiang H. Short-chain fatty acids enhance adipocyte differentiation in the stromal vascular fraction of porcine adipose tissue. J Nutr 2014; 144: 1887-1895.

118 Ge H, Li X, Weiszmann J, Wang P, Baribault H, Chen J-L et al. Activation of G protein-coupled receptor 43 in adipocytes leads to inhibition of lipolysis and suppression of plasma free fatty acids. Endocrinology 2008; 149: 4519-4526.

119 Hosseini A, Behrendt C, Regenhard P, Sauerwein H, Mielenz M. Differential effects of propionate or $\beta$-hydroxybutyrate on genes related to energy balance and insulin sensitivity in bovine white adipose tissue explants from a subcutaneous and a visceral depot1. J Anim Physiol Anim Nutr 2012; 96: 570-580.

120 Han J-H, Kim I-S, Jung S-H, Lee S-G, Son H-Y, Myung C-S. The effects of propionate and valerate on insulin responsiveness for glucose uptake in $3 \mathrm{~T} 3-\mathrm{L} 1$ adipocytes and C2C12 myotubes via G protein-coupled receptor 41. PLoS One 2014; 9: e95268.

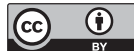

This work is licensed under a Creative Commons Attribution 4.0 International License. The images or other third party material in this article are included in the article's Creative Commons license, unless indicated otherwise in the credit line; if the material is not included under the Creative Commons license, users will need to obtain permission from the license holder to reproduce the material. To view a copy of this license, visit http://creativecommons.org/licenses/ by/4.0/ 